Article

\title{
Cost-Effective Copper-Nickel-Based Triboelectric Nanogenerator for Corrosion-Resistant and High-Output Self-Powered Wearable Electronic Systems
}

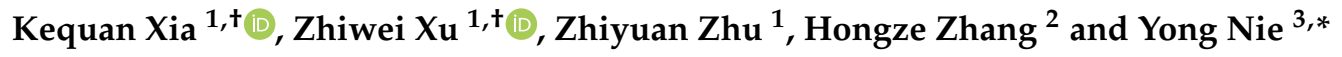 \\ 1 Ocean College, Zhejiang University, Zhoushan 316021, China; 21734118@zju.edu.cn (K.X.); \\ xuzw@zju.edu.cn (Z.X.); 0016180@zju.edu.cn (Z.Z.) \\ 2 Nanjing Electronic Devices Institute 524 East Zhongshan Road, Nanjing 210016, China; \\ zhanghongze007@pku.edu.cn \\ 3 School of Mechanical Engineering, Zhejiang University, Hangzhou 310027, China \\ * Correspondence: ynie@zju.edu.cn; Tel.: +86-137-3813-7016 \\ + These authors contribute equally to this paper.
}

Received: 1 April 2019; Accepted: 26 April 2019; Published: 5 May 2019

\begin{abstract}
Recent years, triboelectric nanogenerators (TENGs) have attracted increased attention from researchers worldwide. Owing to their conductivity and triboelectric characteristics, metal materials can be made as both triboelectric materials and conductive electrodes. However, the surface of typical metals (such as copper, aluminum, and iron) is likely to be corroded when the sweat generated by human-body movement drops on the surface of TENGs, as this corrosion is detrimental to the output performance of TENGs. In this work, we proposed a novel corrosion-resistant copper-nickel based TENG (CN-TENG). Copper-nickel alloy conductive tape and polytetrafluoroethylene (PTFE) tape played the role of the triboelectric materials, and polymethyl methacrylate (PMMA) was utilized as the supporting part. The conductive copper-nickel alloy tape also served as a conductive electrode. The open-circuit voltage $\left(\mathrm{V}_{\mathrm{OC}}\right)$ and short-circuit current $\left(\mathrm{I}_{\mathrm{SC}}\right)$ can arrive at $196.8 \mathrm{~V}$ and $6 \mu \mathrm{A}$, respectively. Furthermore, peak power density values of $45 \mu \mathrm{W} / \mathrm{cm}^{2}$ were realized for the $\mathrm{CN}-\mathrm{TENG}$. A series of experiments confirmed its corrosion-resistant property. The approximate value of $\mathrm{V}_{\mathrm{OC}}$ for the fabricated TENG integrated into the shoe reached $1500 \mathrm{~V}$, which is capable of driving at least 172 high-power LEDs in series. The results of this research provide a workable method for supporting corrosion-resistant self-powered wearable electronics.
\end{abstract}

Keywords: triboelectric nanogenerator; copper-nickel; corrosion-resistant; wearable electrics

\section{Introduction}

In recent years, wearable flexible smart electronics have attracted increasing attention due to the advantages, including low weight, convenience, and multi-functionality [1-5]. Moreover, the rapid development of micro/nanofabrication technology has promoted the ultra-miniaturization and super-integration of wearable electronics [6-8]. However, the power source of wearable electronics remains a bottleneck for their development. Traditional power sources (conventional chemical batteries) are typically large and lead to severe environmental pollution [9-11]. Further, with the continuous development of wireless internet and service upgrades, the energy storage capacity of the traditional batteries that have been used for portable electronics has become inadequate [12-16].

In previous work, some vibration energy harvesters based on piezoelectric and electromagnetic effects are used as considered promising power supply sources for micro-devices, such as 
the tunable multi-frequency vibration energy harvester [17], the structural damping and the electromechanical coupling [18], and the two-degree-of-freedom hybrid piezoelectric-electromagnetic energy harvester [19]. Electromagnetic vibration energy harvesters are widely used due to their small size and adaptability in various harsh environments. However, converting the human-body movement mechanical energy is difficult for previous energy harvesters [20]. Piezoelectric vibration energy harvesters suffer from broad environmental vibration bandwidth and high levels of randomness. Therefore, the harvester and conversion efficiency of these harvesters will decrease significantly [21-23].

In 2012, triboelectric nanogenerators (TENGs) were first proposed as an effective energy harvester of various mechanical motions, including mechanical vibration, human movement, raindrops, and air/water flow [24-30]. TENGs are new types of energy harvesters that are lightweight and flexible with high output performance [31-35]. They are also referred to as green batteries, as they generate less pollution than traditional batteries, such as lead-acid and Ni-Cd batteries [36,37]. Previous works have proposed TENGs that are based on vertical separation, which are defined as the dielectric-to-dielectric TENGs in vertical separation mode [38]. Subsequently, a new approach to prepare TENGs without the depositing metal electrodes are proposed and defined as the conductor-to-dielectric TENG in vertical separation mode [39].

However, the conductor-to-dielectric triboelectric mode requires electronic conductivity for one of a triboelectric pair. Thus, various metal materials including copper, aluminum, and iron [40-42] have been used for the fabrication of the conductor-to-dielectric TENG. It is obvious that the characteristics of the triboelectric materials' surface are crucial for the electrical output of TENG, especially considering that the surface of metal materials becomes corroded when the sweat generated by human-body movement drops on the surface of TENGs. This corrosion may also be detrimental to the electronic output performance. Thus, a corrosion-resistant metal material is essential for wearable TENGs. $\mathrm{Li}$ et al. have recently proposed a humidity-resisting triboelectric nanogenerator that can provide stable output performance in high humidity environments. However, it is not based on a metal triboelectric material, and the output power density is relatively low, which greatly limits its application. However, roughening triboelectric surfaces can be used as a practical method to increase the electrical output of TENG. Therefore, it is urgent to propose a cost-effective, corrosion-resistant, conductor-to-dielectric TENG with high output performance.

In this paper, we firstly developed a novel copper-nickel-based TENG (CN-TENG) composed of conductive copper-nickel alloy tape and polytetrafluoroethylene (PTFE) tape. Polymethyl methacrylate (PMMA) was utilized as the supporting structure. The copper-nickel alloy tape plays the role of the triboelectric pair and as conductive electrodes, due to its strong ability to lose electrons and its excellent electrical conductivity. Simultaneously, the rough surface of the copper-nickel alloy enables high output performance without additional surface roughening treatment, which significantly reduces processing costs and increases the output compared with other conductive metal, such as conductive copper, for example. Furthermore, the results obtained from a series of experiments revealed that the conductive copper-nickel alloy enabled the corrosion-resistant property of the proposed CN-TENG. The materials used for the TENG fabrication, including the alloy tape, PTFE tape, PMMA, and copper foil, are all common commodities in our daily life. The open-circuit voltage $\left(\mathrm{V}_{\mathrm{OC}}\right)$ and short-circuit current (ISC) can arrive at $196.8 \mathrm{~V}$ and $6 \mu \mathrm{A}$, respectively, and peak power density values of $45 \mu \mathrm{W} / \mathrm{cm}^{2}$ were realized for the CN-TENG. The experimental results revealed that the approximate value of $\mathrm{V}_{\mathrm{OC}}$ of the fabricated CN-TENG integrated into the shoe reaches a maximum value of $1500 \mathrm{~V}$, which is capable of driving at least 172 high-power light-emitting diodes (LEDs) in series.

\section{Materials and Methods}

The preparation process of CN-TENG is shown in Figure 1a. As demonstrated in Figure 1(a1), a piece of $3 \mathrm{~cm} \times 6 \mathrm{~cm}$ transparent PMMA is used as a substrate. Subsequently, two pieces of $2 \mathrm{~cm} \times$ $3 \mathrm{~cm}$ conductive copper-nickel alloy tape are attached on a PMMA substrate (see Figure 1(a2)). Then, the PTFE tape is applied to the surface of the copper foil, as illustrated in Figure 1(a3). Afterward, 
the substrate is folded into the device such that the PTFE tape surface faces the copper-nickel alloy tape surface, as illustrated in Figure 1(a4) and shown in Figure 1b. A stacked TENG is developed (see Figure 1(a5)) to strengthen the output current of the fabricated TENG. The SEM images in Figure 1c,d show the surfaces of the PTFE tape and the conductive tape. The fabric structure of the conductive copper-nickel alloy tape surface can increase the roughness of the triboelectric material, thereby enhancing the output performance of the TENG. The digital oscilloscope is utilized to measure electrical output. The fabricated TENG was activated by a vibrator (amplitude and frequency: $5 \mathrm{~mm}$ and $5 \mathrm{~Hz}$, respectively), and a picture of the experimental setup is illustrated in Figure 1e.

(a)
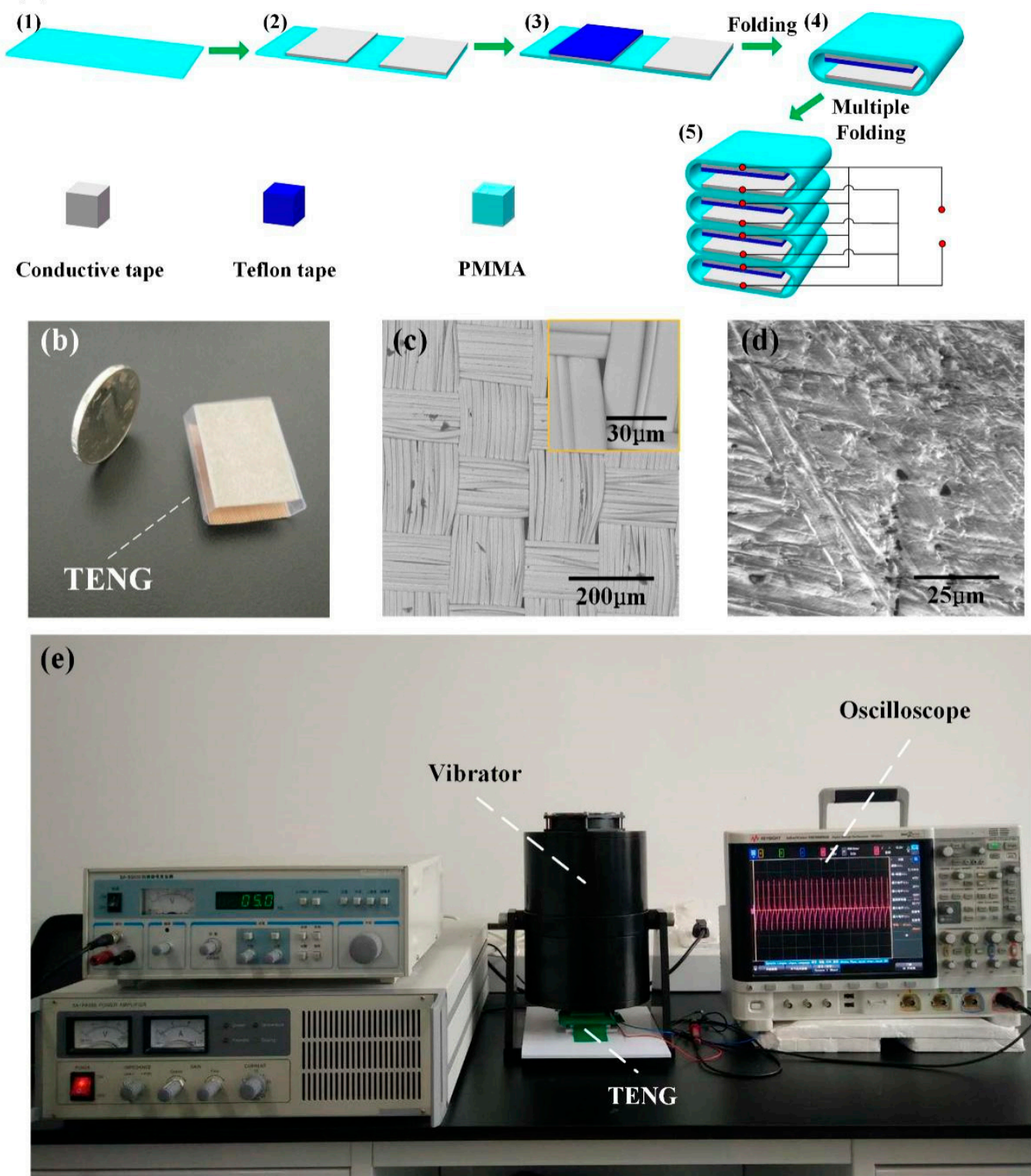

Figure 1. (a) Preparation process of the copper-nickel-based triboelectric nanogenerator (CN-TENG). (b) Photograph of the fabricated CN-TENG unit. SEM image showing the surface of the (c) conductive tape and (d) polytetrafluoroethylene (PTFE) tape. (e) The mechanical vibration system and measurement system. 


\section{Results and Discussion}

Figure 2a shows a schematic illustrating the working mechanism of the CN-TENG. When PTFE film and conductive tape contact with each other, electrons will be injected from copper-nickel metal film into PTFE, in accordance with the electron-attraction ability of the materials. During full contact, the metal side is in electrical equilibrium. An electric potential difference can be constructed when PTFE separates from metal. This difference drives electron flow (owing to external loads) from the top electrode to the bottom electrode, and generates an electrical output signal. When the largest separation distance is reached in a complete contact-separation cycle, a new electrical equilibrium will be set up. Subsequently, if the PTFE is brought toward the conductive tape surface, then the electrons flow back to the top electrode, producing a reversed output current signal. The original state of the CN-TENG is restored with subsequent full contact between the PTFE and the conductive tape. Continuous electric output is engendered by periodic contact between the PTFE and the conductive tape. To elucidate the operation of the CN-TENG, the potential distribution was simulated using the COMSOL multi-physics software, as presented in Figure $2 b$. According to the simulation results, when displacement between two triboelectric materials increases, the potential difference also sharply increases.

(a)
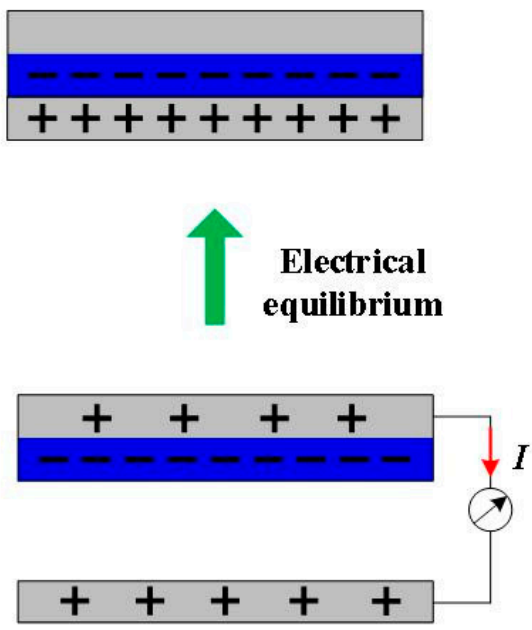

(b)

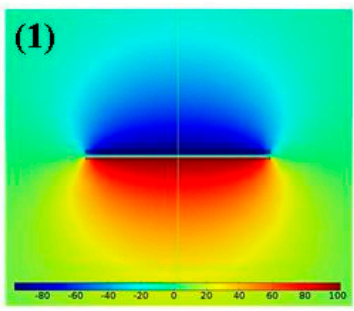

Pressing
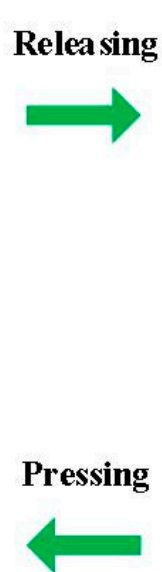

\section{Electrical equilibrium}
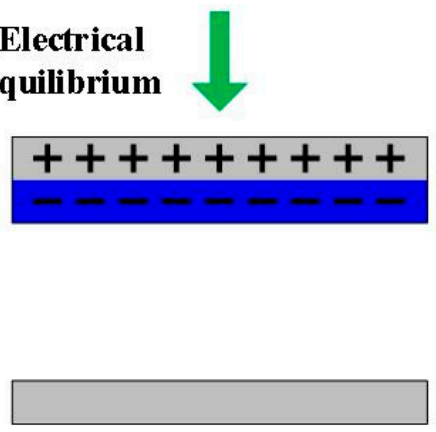
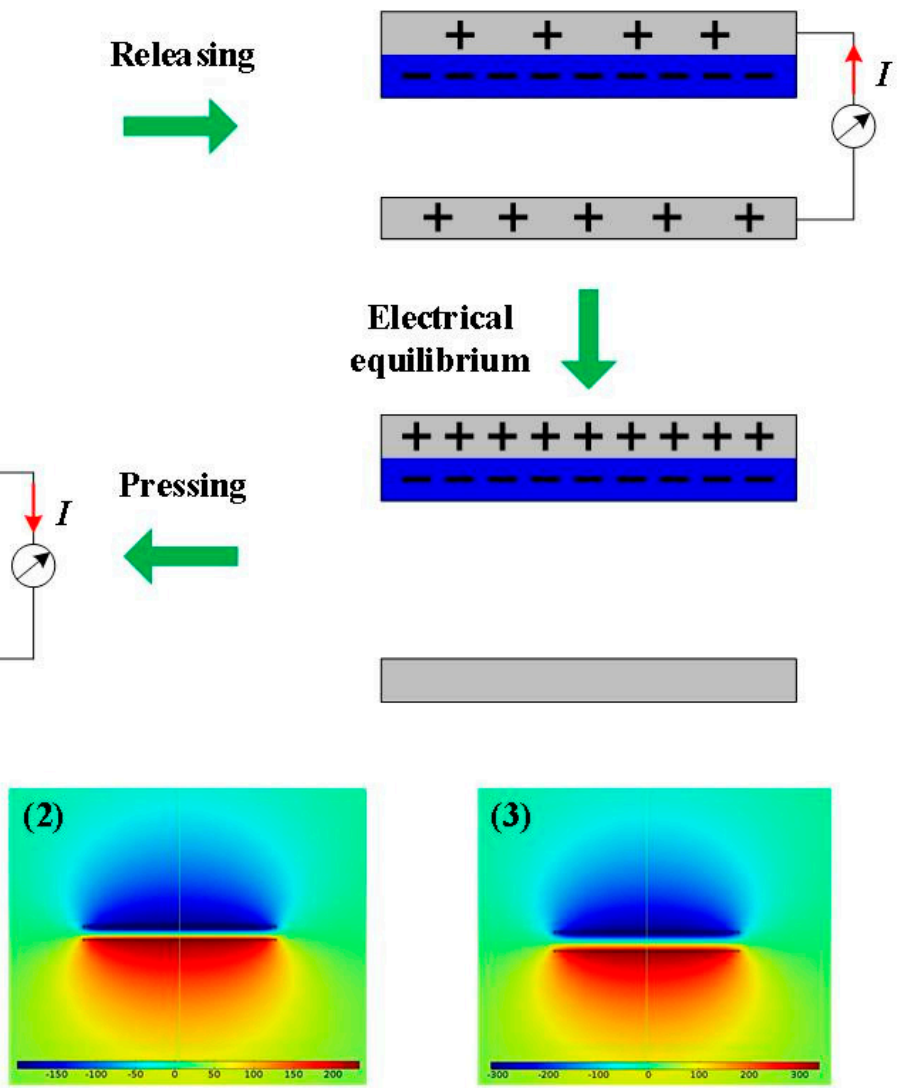

Figure 2. (a) Working mechanism of the CN-TENG. (b) Numerical calculations (performed in COMSOL) of the potential distribution across the electrodes of the TENG at each step (1-3) under open-circuit conditions.

The external force was provided by a vibration exciter to activate CN-TENG. As shown in Figure $3 a, b$, the performance of TENG (the size: $2 \mathrm{~cm} \times 3 \mathrm{~cm}$ ) was characterized by approximate values of the $\mathrm{V}_{\mathrm{OC}}$ (under the external load of $500 \mathrm{M} \Omega$ ) and $\mathrm{I}_{\mathrm{SC}}$ (under the external load of $100 \mathrm{~K} \Omega$ ), which reached values of $196.8 \mathrm{~V}$ and $6 \mu \mathrm{A}$, respectively. As illustrated in Figure 3c, for resistance lower than $100 \mathrm{~K} \Omega$, the output current was $\sim 6 \mu \mathrm{A}$. The output voltage increased to $>196.8 \mathrm{~V}$ when the 
resistance increased from $100 \mathrm{~K} \Omega$ to $500 \mathrm{M} \Omega$. The maximum power density can arrive at $45 \mu \mathrm{W} / \mathrm{cm}^{2}$, which occurred at $30 \mathrm{M} \Omega$, as shown in Figure $3 \mathrm{~d}$.

(a)

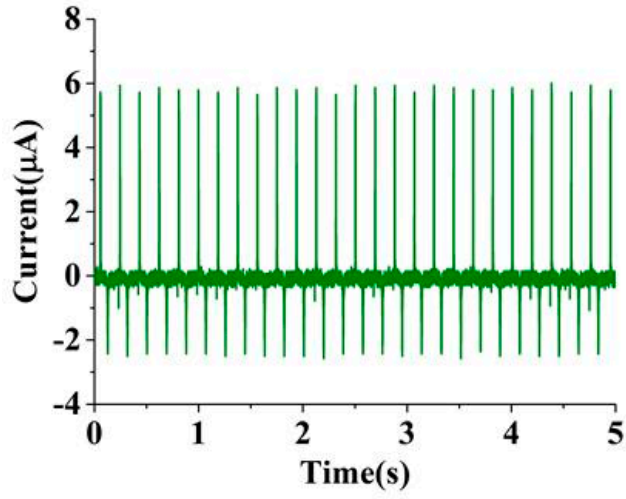

(c)

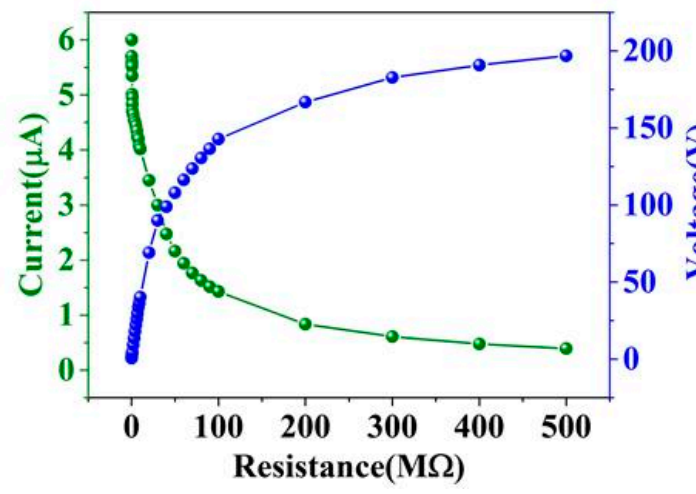

(b)

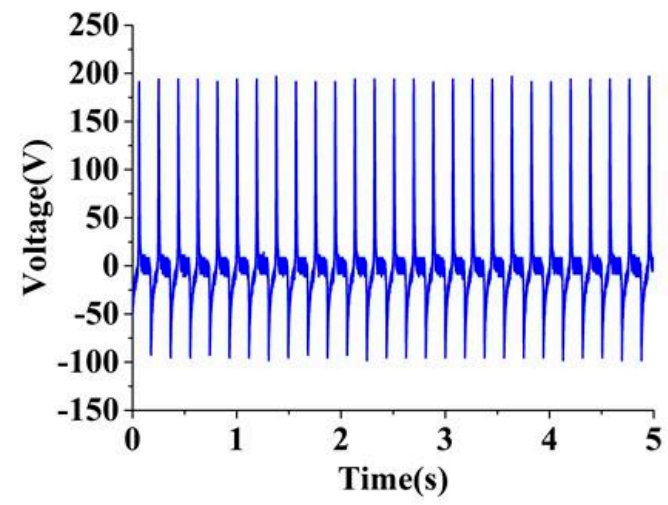

(d)

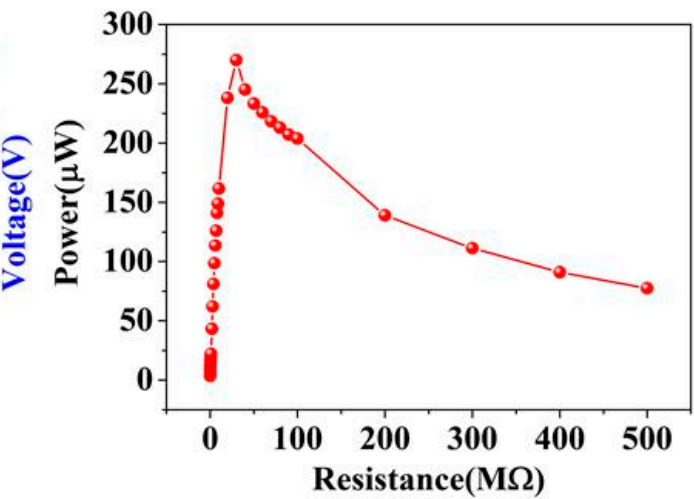

Figure 3. The (a) output current, (b) voltage of the TENG unit, (c) output voltage and current versus different load resistances, and (d) corresponding output power density under various load resistances.

To improve the electrical output, a stacked CN-TENG was developed. The output performance of stacked TENGs with different numbers of working units were measured, and approximate ISC values of $10.2 \mu \mathrm{A}, 13.7 \mu \mathrm{A}$, and $18.2 \mu \mathrm{A}$, respectively, were obtained (see Figure 4a-c). Additionally, the output current obtained for different numbers of units was compared, as shown in Figure 4d. According to the results, the output current increased with as the number of units increased.

We compared the charging ability of CN-TENG and conventional TENG (based on conductive copper) by charging a 1-nF capacitor through a full-wave rectifier bridge. As illustrated in Figure 5a, at the peak value of the capacitor voltage (i.e., $21 \mathrm{~V}$ ), $21 \mathrm{nC}$ of charge was transferred for CN-TENG. However, for conventional TENG, only $13 \mathrm{nC}$ of charge was transferred (see Figure $5 \mathrm{~b}$ ). The relatively high charge transfer $(21 \mathrm{nC})$ is attributed to the rough surface of the conductive copper-nickel alloy tape, which produces more induced triboelectric charges due to the increased contact area. Moreover, the fabricated CN-TENG was tested by using a vibration platform, and the results revealed that the output voltage of the TENG stays stable even after 5000 cycles, as shown in Figure 5c.

Regarding wearable electronics, the corrosion resistance of the device has a significant influence on the electrical output. This investigation is important, as humans will sweat profusely during exercise activities. Therefore, the electrical output performance and the conventional copper TENG subjected to a corrosive environment was compared. In detail, both devices were immersed in a sodium chloride solution (mass fraction: 5\%,15\%, and 25\%) for $10 \mathrm{~h}$, followed by subsequent exposure to air for $2 \mathrm{~h}$. Afterward, the output performance was measured. 
(a)

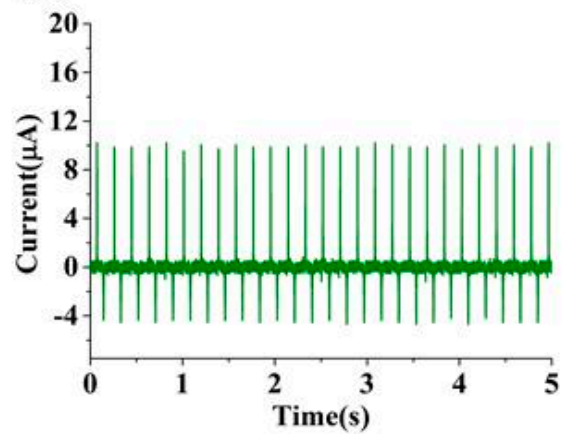

(c)

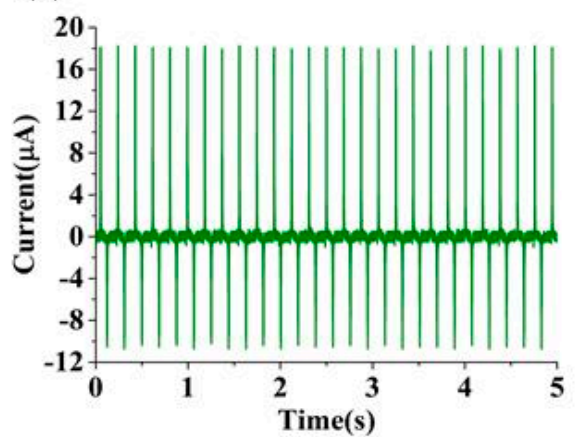

(b)

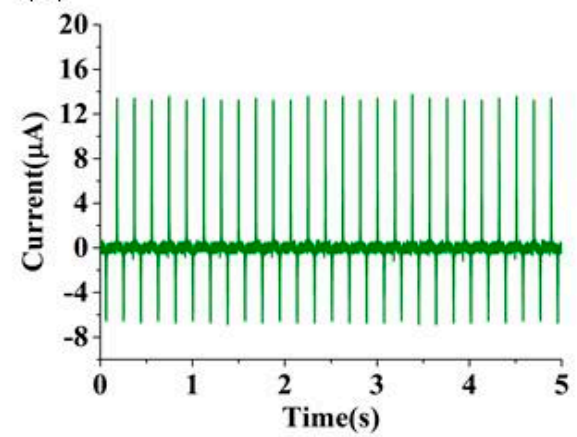

(d)

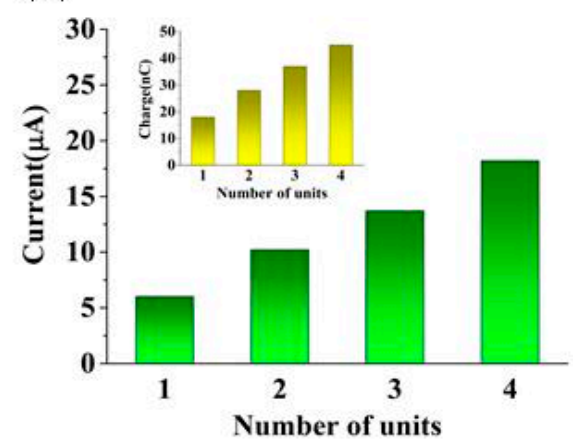

Figure 4. Characterization of a CN-TENG output with different unit numbers. The approximate ISC value of the CN-TENG with (a) two units, (b) three units, and (c) four units. (d) Comparison of output performance.

(a)

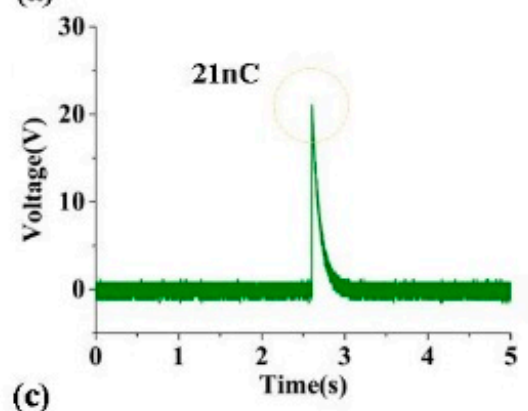

(c)

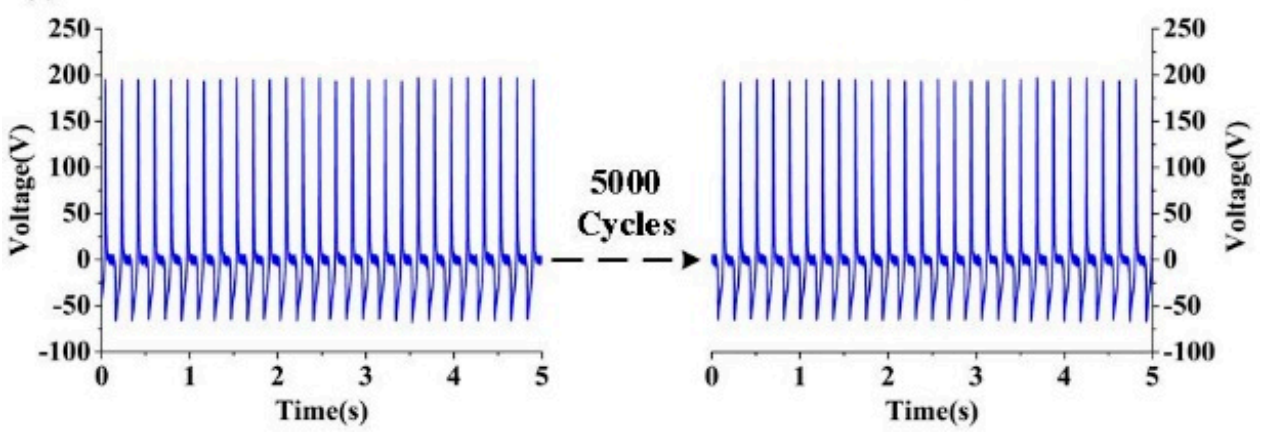

Figure 5. (a) The voltage curve of a 1-nF capacitor connected to the TENGs through a full-wave rectifier bridge, and (b) conductive copper tape, respectively, which serve as the triboelectric pairs. (c) The reliability of the prepared TENG was verified via 5000 cycles of continuous operation. 
Figure 6 shows the electrical measurement of copper TENGs treated with different concentrations of sodium chloride solution. Approximate $\mathrm{V}_{\mathrm{OC}}$ values of $150 \mathrm{~V}, 101 \mathrm{~V}$, and $70 \mathrm{~V}$; ISC values of $5 \mu \mathrm{A}, 3.4 \mu \mathrm{A}$, and $2.1 \mu \mathrm{A}$, and output power values of $187 \mu \mathrm{W}, 93 \mu \mathrm{W}$, and $40 \mu \mathrm{W}$ were realized at the aforementioned mass fractions (see Figure 6a-f). Corresponding values of $160 \mathrm{~V}, 5.7 \mu \mathrm{A}$, and $220 \mu \mathrm{W}$, which were obtained for the untreated TENG, were set as the reference values. Additionally, approximate $V_{O C}$ values, ISC values, and the maximum output power value of TENGs smeared with different mass fractions of the chloride solution were compared, as illustrated in Figure $6 \mathrm{~g}-\mathrm{i}$. The results display that the output performance decreased with the increasing mass fraction of the solution. This decrease can be attributed to the weak corrosion resistance of the conductive copper.

(a)

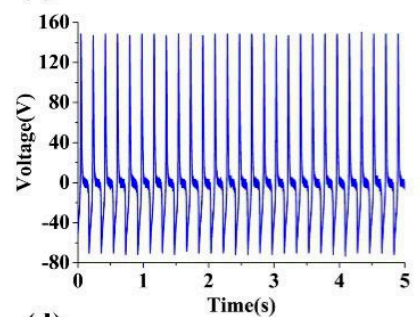

(d)

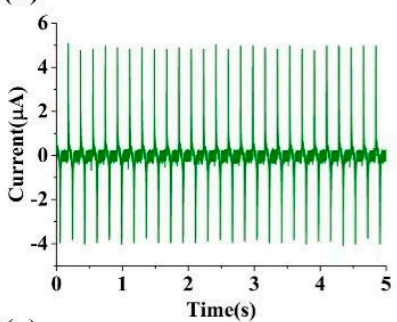

(g)

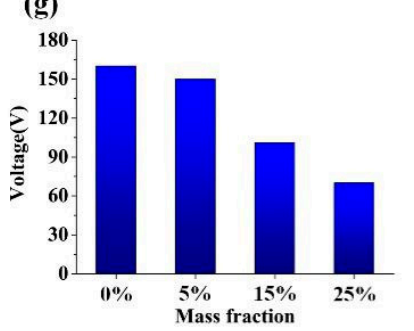

(b)

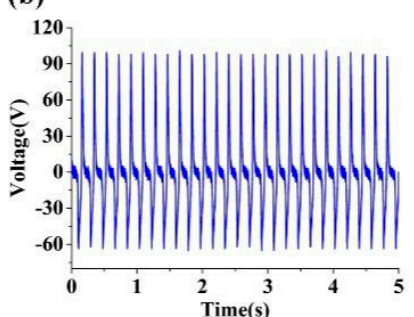

(e)

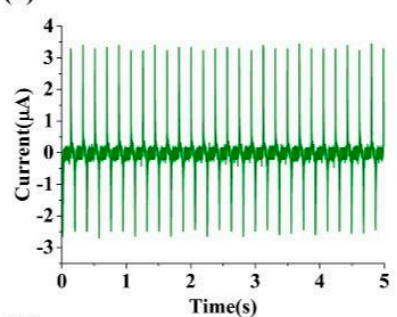

(h)

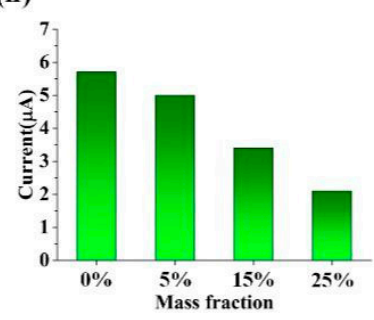

(c)

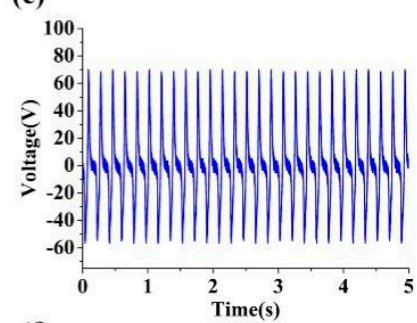

(f)

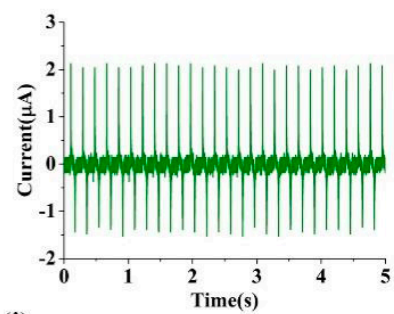

(i)

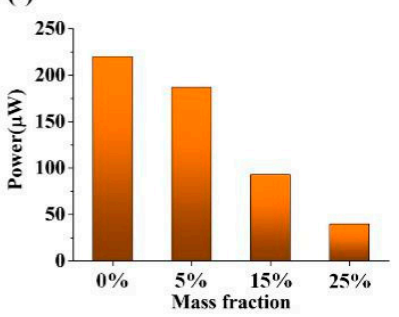

Figure 6. Electrical measurements of three copper TENGs treated with different concentrations of a sodium chloride solution. (a-c) Approximate open-circuit voltage (Voc) and (d-f) short-circuit current $\left(\mathrm{I}_{\mathrm{SC}}\right)$ values of the treated copper TENGs. Comparison of the approximate Voc $(\mathbf{g}), \mathrm{I}_{\mathrm{SC}}(\mathbf{h})$, and value of max output (i) power for the copper TENGs.

The investigations under the same experimental conditions were performed on the CN-TENG. Based on the experimental results, approximate $\mathrm{V}_{\mathrm{OC}}$ and $\mathrm{I}_{\mathrm{SC}}$ values were measured, as shown in Figure 7a-f. Approximate $\mathrm{V}_{\mathrm{OC}}$ values of $195 \mathrm{~V}, 191 \mathrm{~V}$, and $187 \mathrm{~V}$; ISC values of $5.8 \mu \mathrm{A}, 5.7 \mu \mathrm{A}$, and $5.5 \mu \mathrm{A}$; and output power values of $268 \mu \mathrm{W}, 252 \mu \mathrm{W}$, and $241 \mu \mathrm{W}$, were realized for the treated CN-TENGs.

The aforementioned experimental results revealed approximate $\mathrm{V}_{\mathrm{OC}}, \mathrm{I}_{\mathrm{SC}}$, and maximum output power values of $196.8 \mathrm{~V}, 6 \mu \mathrm{A}$, and $270 \mu \mathrm{W}$, respectively, for the untreated CN-TENG, and these values were set as the reference values. Additionally, the approximate $\mathrm{V}_{\mathrm{OC}}, \mathrm{I}_{\mathrm{SC}}$, and maximum output power values of the TENGs smeared with different mass fractions of the chloride solution were compared, as presented in Figure 7g-i. According to the figure, each of these values decreased only slightly as the mass fraction of the solution increased. This is attributed to the excellent corrosion resistance of the conductive copper tape with nicked, compared with that of the conductive copper tape. It is noted that 
copper will undergo electrochemical corrosion in sodium chloride solution [41]. The related chemical reaction equations are as follows.

$$
2 \mathrm{Cu}+\mathrm{H}_{2} \mathrm{O}+\mathrm{CO}_{2}+\mathrm{O}_{2}=\mathrm{Cu}_{2}(\mathrm{OH})_{2} \mathrm{CO}_{3}
$$

The basic cupric carbonate produced by the reaction not only affects the electrical output of TENG, but also damages human health. However, the copper-nickel alloy has good corrosion resistance in the corresponding environment [42]. In order to visualize the corrosion on the surface of the copper foil, we analyzed the elements on the copper foil surface by sodium chloride solution (shown in Figure 8b), and compared the copper foil surface before treatment (shown in Figure 8a). According to the results, the proportion of copper elements on the surface of the treated copper decreased obviously, which will influence the electrical output of the TENG.

(a)

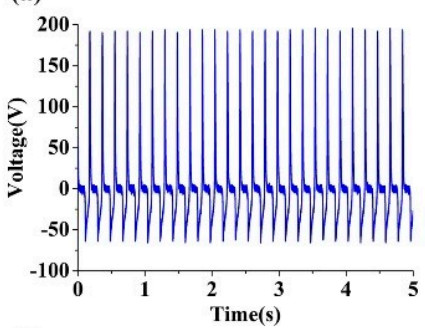

(d)

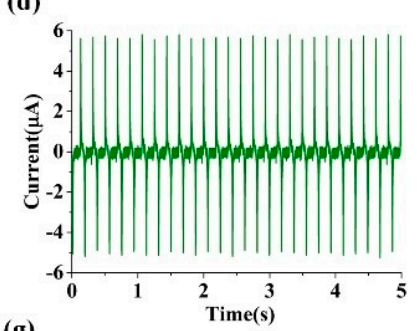

(g)

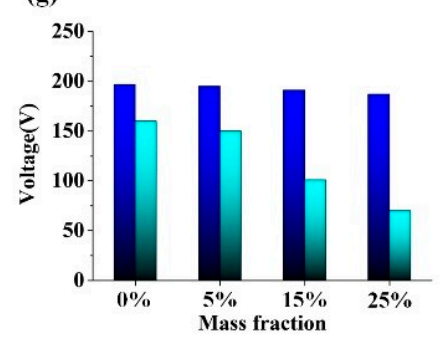

(b)

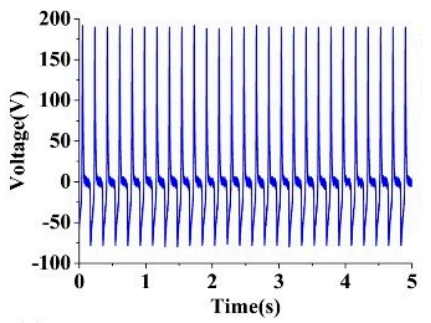

(e)

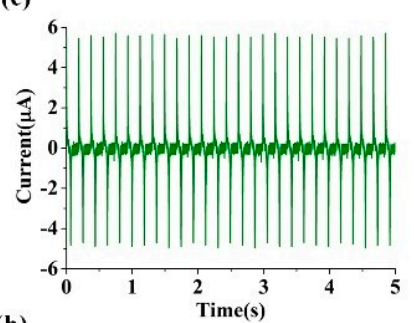

(h)

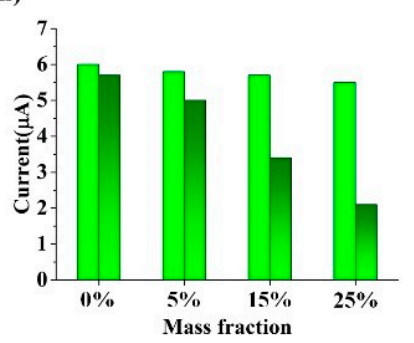

(c)

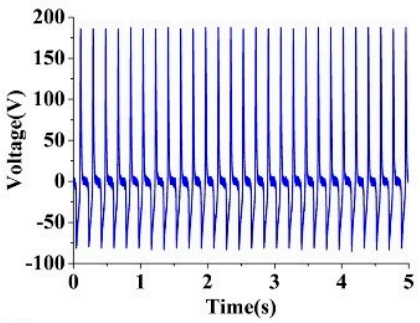

(f)

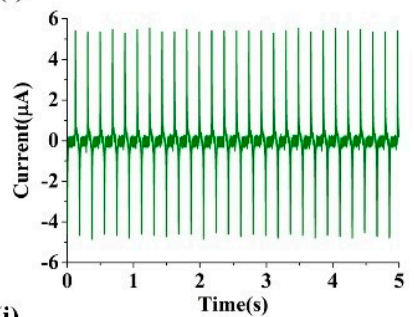

(i)

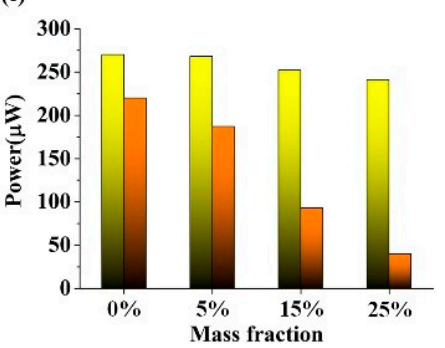

Figure 7. Electrical measurement of three CN-TENGs treated with different concentrations of sodium chloride solution. $(\mathbf{a}-\mathbf{c})$ Approximate $\mathrm{V}_{\mathrm{OC}}$ and $(\mathbf{d}-\mathbf{f}) \mathrm{I}_{\mathrm{SC}}$ values of the treated CN-TENGs. Comparison of the approximate $\mathrm{V}_{\mathrm{OC}}(\mathbf{g})$, ISC $(\mathbf{h})$, and the value of max output (i) power for the CN-TENGs.

In addition, we demonstrated that the $5 \mathrm{~cm} \times 20 \mathrm{~cm}$ CN-TENG can be easily integrated into a shoe, as shown in Figure 9b. When people are exercising, the CN-TENG integrated into shoe can be utilized to harvest mechanical energy, as shown in Figure 9a. The frequency of human motion is about $4 \mathrm{~Hz}$, and the test time is $5 \mathrm{~s}$. As the experimental results show (see Figure 9c), an approximate $\mathrm{V}_{\mathrm{OC}}$ value of $1500 \mathrm{~V}$ is realized for the TENG in the shoe sole. Owing to the walking action, the TENG is capable of driving at least 172 high-power LEDs in series (working voltage: $3.4 \mathrm{~V}$ ), as shown in Figure 9d,e. 


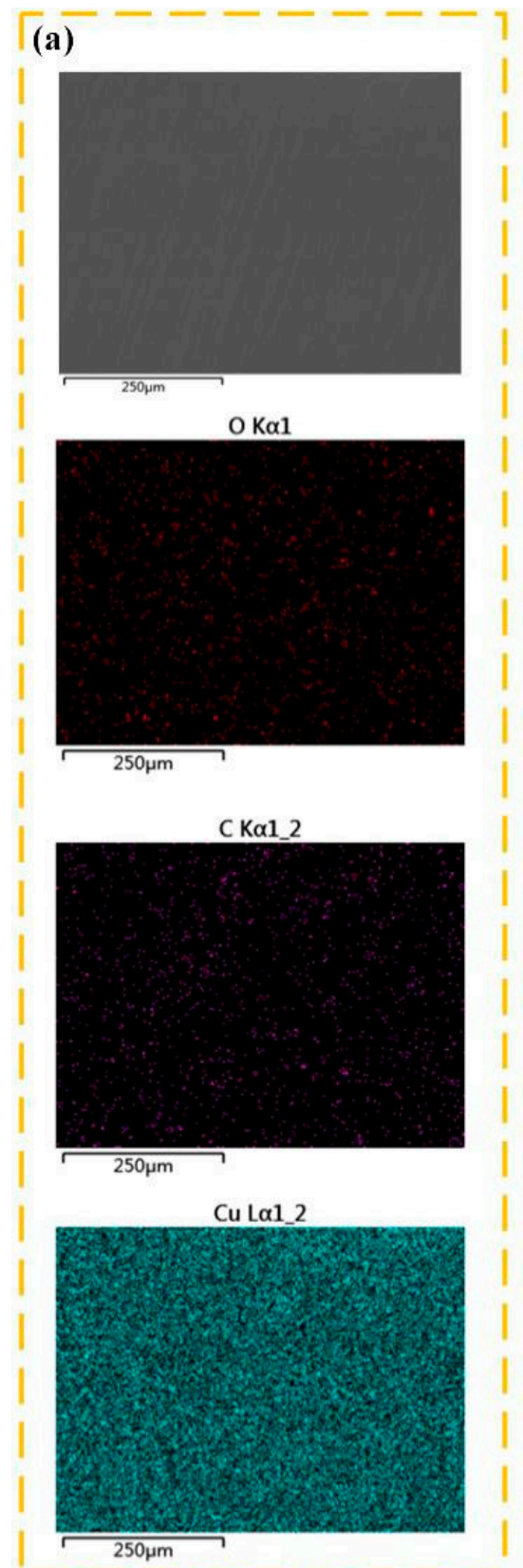

\section{(b)}
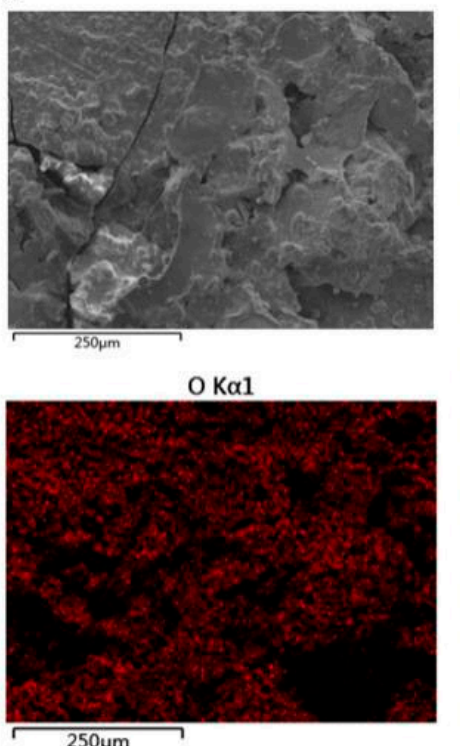

$250 \mu \mathrm{m}$

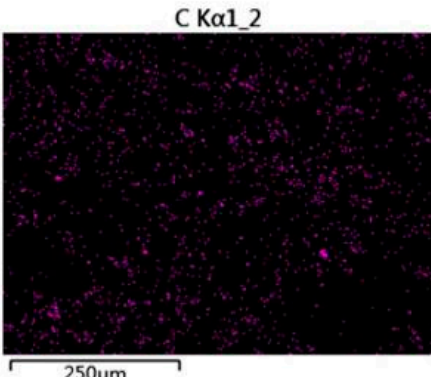

Cu L $\alpha 1 \_2$

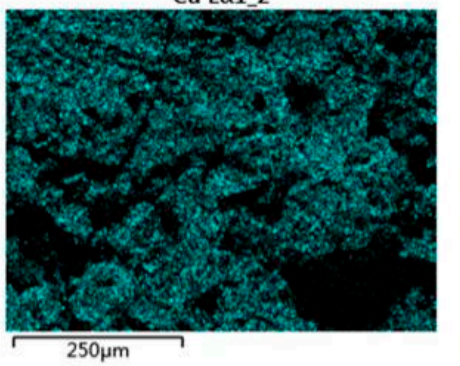

$\mathrm{Cl} \mathrm{K \alpha 1}$
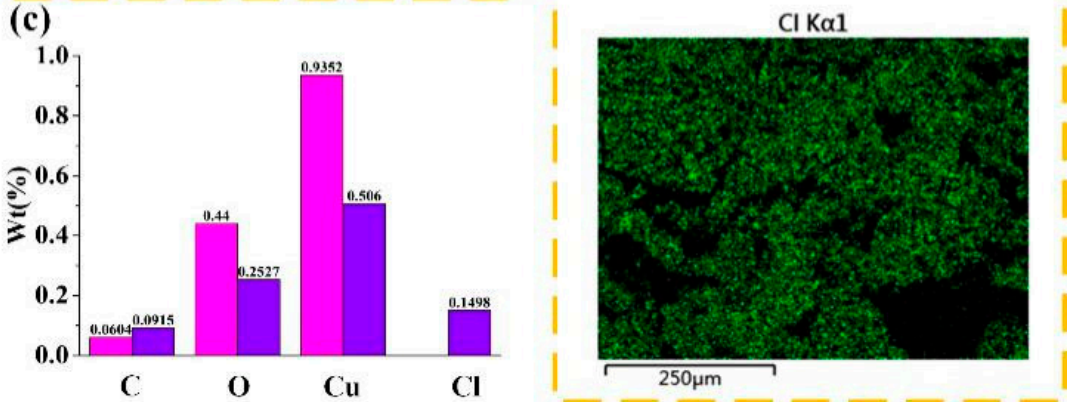

Figure 8. Elemental analysis of (a) the surface of the copper foil and (b) the copper foil surface treated with sodium chloride solution. (c) Comparison of element proportion on the copper foil surface treated with sodium chloride solution. 

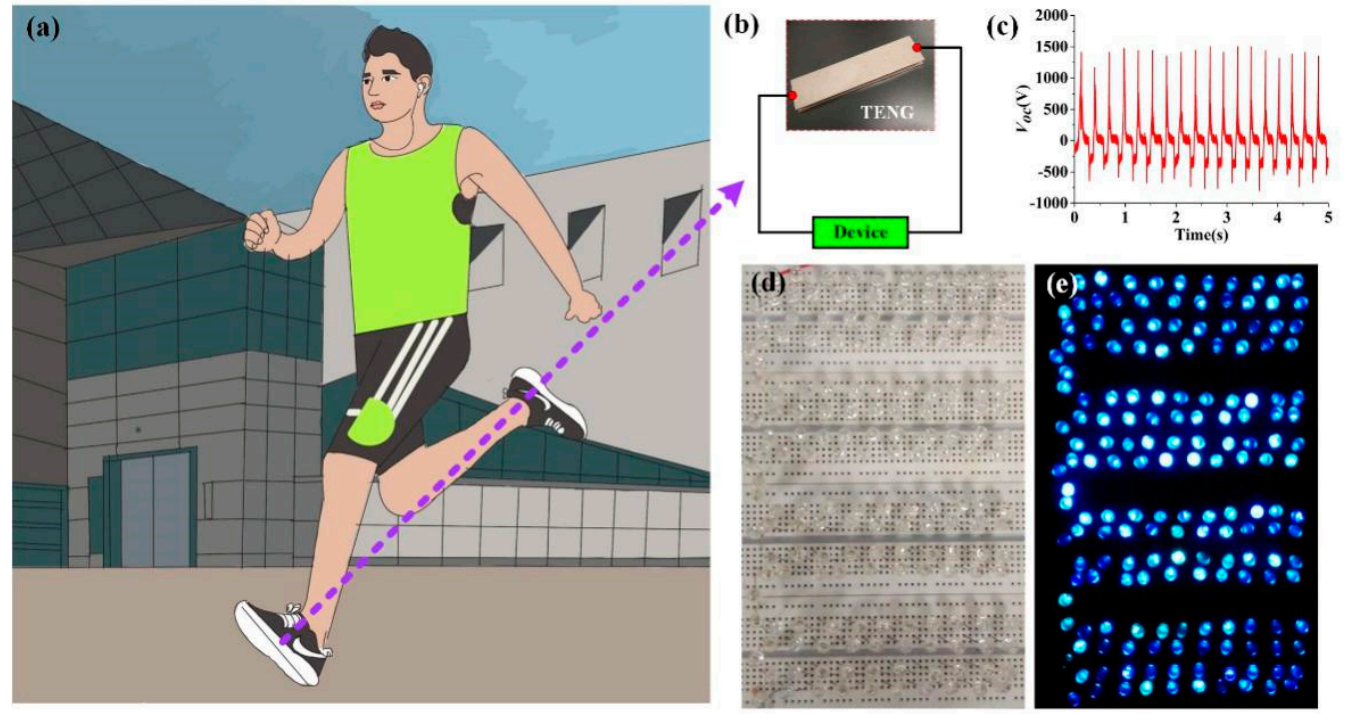

Figure 9. (a) The schematic of human walking. (b) Picture of the $5 \mathrm{~cm} \times 20 \mathrm{~cm}$ fabricated TENG integrated into a shoe. (c) Approximate VOC of the TENG generated during human walking. (d,e) Photograph of the 172 high-power light-emitting diodes (LEDs) easily driven by the TENG during human walking.

\section{Conclusions}

A novel CN-TENG was developed using conductive copper-nickel alloy tape and PTFE tape. The copper-nickel alloy tape played the role of the triboelectric pair and conductive electrodes; PMMA was utilized as the supporting structure. The materials utilized for the fabricated TENG, including the alloy tape, PTFE tape, PMMA, and copper foil, are all common commodities in our daily life. The $\mathrm{V}_{\mathrm{OC}}$ and $\mathrm{I}_{\mathrm{SC}}$ values can arrive at $196.8 \mathrm{~V}$ and $6 \mu \mathrm{A}$, respectively, and peak power density values of $45 \mu \mathrm{W} / \mathrm{cm}^{2}$ were realized for the CN-TENG. To boost the output current, a stacked CN-TENG was fabricated, and the enhanced corresponding output performance was observed. A series of experiments demonstrate the excellent corrosion resistance of the proposed CN-TENG. In addition, we demonstrated that the TENG can be easily integrated into a shoe and operated by the movement of walking. From the experimental results, the approximate $V_{O C}$ value of the fabricated TENG in the shoe reached $1500 \mathrm{~V}$, which is capable of driving at least 172 high-power LEDs in series. The proposed TENG can be applied in the field of wearable electronics and serve as a continuous energy supply.

Author Contributions: Conceptualization, K.X. and Z.X.; Methodology, K.X.; Software, K.X.; Validation, H.Z. and Y.N.; Formal Analysis, Z.Z.; Investigation, K.X.; Resources, Y.N.; Data Curation, Y.N.; Writing-Original Draft Preparation, Y.N.; Writing-Review \& Editing, K.X.; Visualization, Y.N.; Supervision, Z.X.; Project Administration, Y.N.; Funding Acquisition, Y.N.

Funding: This research was funded by [National Natural Science Foundation of China] grant number [Grant No. 61804132, Grant No. 61674128, Grant No. 61731019] and The APC was funded by [ Aeronautical Science Foundation: ASFC-2017ZC76002].

Conflicts of Interest: The authors declare no conflict of interest.

\section{References}

1. Song, J.K.; Son, D.; Kim, J.; Yoo, Y.J.; Lee, G.J.; Wang, L.; Choi, M.K.; Yang, J.; Lee, M.; Do, K.; et al. Wearable Force Touch Sensor Array Using a Flexible and Transparent Electrode. Adv. Funct. Mater. 2017, 6, 1605286. [CrossRef]

2. Wang, G.; Huang, W.; Eastham, N.D.; Fabiano, S.; Manley, E.F.; Zeng, L.; Wang, B.; Zhang, X.N.; Chen, Z.H.; Li, R.; et al. Aggregation control in natural brush-printed conjugated polymer films and implications for enhancing charge transport. Proc. Natl. Acad. Sci. USA 2017, 47, 10066-10073. [CrossRef] [PubMed] 
3. Ge, X.; Gu, C.D.; Wang, X.L.; Tu, J.P. Deep eutectic solvents (DESs)-derived advanced functional materials for energy and environmental applications: Challenges, opportunities, and future vision. J. Mater. Chem. A 2017, 18, 8209-8229. [CrossRef]

4. Pu, X.; Song, W.X.; Liu, M.M.; Sun, C.W.; Du, C.H.; Jiang, C.Y.; Huang, X.; Zou, D.C.; Hu, W.G.; Wang, Z.L. Wearable Power-Textiles by Integrating Fabric Triboelectric Nanogenerators and Fiber-Shaped Dye-Sensitized Solar Cells. Adv. Energy Mater. 2016, 20, 1601048. [CrossRef]

5. Wang, X.G.; Peng, W.B.; Yu, R.M.; Zou, H.Y.; Dai, Y.J.; Zi, Y.L.; Wu, C.S.; Li, S.T.; Wang, Z.L. Simultaneously Enhancing Light Emission and Suppressing Efficiency Droop in GaN Microwire-Based Ultraviolet Light-Emitting Diode by the Piezo-Phototronic Effect. Nano Lett. 2017, 6, 3718-3724. [CrossRef] [PubMed]

6. Boonsorn, W.; Watcharamaisakul, S.; Golman, B. Fabrication of Al2O3/ZrO2 Micro/Nano Composites Using Powder Alkoxide Mixtures. Adv. Mater. Res. 2014, 931, 132-136. [CrossRef]

7. Gu, L.; Cui, N.Y.; Liu, J.M.; Zheng, Y.B.; Bai, S.; Qin, Y. Packaged triboelectric nanogenerator with high endurability for severe environments. Nanoscale 2015, 7, 18049-18053. [CrossRef] [PubMed]

8. Lu, C.X.; Han, C.B.; Gu, G.Q.; Chen, J.; Yang, Z.W.; Jiang, T.; He, C.; Wang, Z.L. Temperature Effect on Performance of Triboelectric Nanogenerator. Adv. Eng. Mater. 2017, 12, 1700275. [CrossRef]

9. Xi, Y.; Guo, H.Y.; Zi, Y.L.; Li, X.G.; Wang, J.; Deng, J.N.; Li, S.M.; Hu, C.G.; Cao, X.; Wang, Z.L. Multifunctional TENG for Blue Energy Scavenging and Self-Powered Wind-Speed Sensor. Adv. Energy Mater. 2017, 12, 1602397. [CrossRef]

10. Liu, Z.F.; Chen, Y.X.; Zhuo, R.Q.; Jia, H.J. Energy storage capacity optimization for autonomy microgrid considering CHP and EV scheduling. Appl. Energy 2018, 210, 1113-1125. [CrossRef]

11. Khan, A.S.M.; Verzijlbergh, R.A.; Sakinci, O.C.; De Vries, L.J. How do demand response and electrical energy storage affect (the need for) a capacity market. Appl. Energy 2018, 214, 39-62. [CrossRef]

12. Wei, G.; Bi, Y.; Li, X.; Xu, D.; Xu, W.; Yang, L.; Qin, Y.; Guo, H.; Zhao, X.; Chen, X.; et al. Self-powered hybrid flexible nanogenerator and its application inbionic micro aerial vehicles. Nano Energy 2018, 54, $10-16$. [CrossRef]

13. Zhang, X.S.; Han, M.D.; Kim, B.; Bao, J.F.; Brugger, J.; Zhang, H.X. All-in-one self-powered flexible microsystems based on triboelectric nanogenerators. Nano Energy 2018, 47, 410-426. [CrossRef]

14. Li, X.H.; Lin, Z.H.; Cheng, G.; Wen, X.N.; Liu, Y.; Niu, S.M.; Wang, Z.L. 3D Fiber-Based Hybrid Nanogenerator for Energy Harvesting and as a Self-Powered Pressure Sensor. ACS Nano 2014, 10, 10674-10681. [CrossRef]

15. Wu, C.S.; Ding, W.B.; Liu, R.Y.; Wang, J.Y.; Wang, A.C.; Wang, J.; Li, S.M.; Zi, Y.L.; Wang, Z.L. Keystroke dynamics enabled authentication and identification using triboelectric nanogenerator array. Mater. Today 2018, 21, 216-222. [CrossRef]

16. Tang, W.; Han, C.B.; Zhang, C.; Zhang, Z.L. Cover-sheet-based nanogenerator for charging mobile electronics using low-frequency body motion/vibration. Nano Energy 2014, 9, 121-127. [CrossRef]

17. Zhang, X.S.; Brugger, J.; Kim, B. A silk-fibroin-based transparent triboelectric generator suitable for autonomous sensor network. Nano Energy 2016, 20, 37-47. [CrossRef]

18. Li, X.H.; Yeh, M.H.; Lin, Z.H.; Guo, H.Y.; Yang, P.K.; Wang, J.; Wang, S.H.; Yu, R.M.; Zhang, T.J.; Wang, Z.L. Self-Powered Triboelectric Nanosensor for Microfluidics and Cavity-Confined Solution Chemistry. ACS Nano 2015, 9, 11056-11063. [CrossRef] [PubMed]

19. Zhang, X.S.; Han, M.D.; Meng, B.; Zhang, H.X. High performance triboelectric nanogenerators based on large-scale mass-fabrication technologies. Nano Energy 2015, 11, 304-322. [CrossRef]

20. Xia, K.Q.; Zhu, Z.Y.; Zhang, H.Z.; Du, C.L.; Xu, Z.W.; Wang, R.J. Painting a high-output triboelectric nanogenerator on paper for harvesting energy from human body motion. Nano Energy 2018, 50, 571-580. [CrossRef]

21. Guo, H.Y.; Yeh, M.H.; Lai, Y.C.; Zi, Y.L.; Wu, C.S.; Wen, Z.; Hu, C.G.; Wang, Z.L. All-in-One Shape-Adaptive Self-Charging Power Package for Wearable Electronics. ACS Nano 2016, 11, 10580-10588. [CrossRef]

22. Yang, P.K.; Lin, Z.H.; Pradel, K.C.; Lin, L.; Li, X.H.; Wen, X.N.; He, J.H.; Wang, Z.L. Paper-Based Origami Triboelectric Nanogenerators and Self-Powered Pressure Sensors. ACS Nano 2015, 1, 901-907. [CrossRef] [PubMed]

23. Zhang, X.S.; Han, M.D.; Wang, R.X.; Meng, B.; Zhu, F.Y.; Sun, X.M.; Hu, W.; Wang, W.; Li, Z.H.; Zhang, H.X. High-performance triboelectric nanogenerator with enhanced energy density based on single-step fluorocarbon plasma treatment. Nano Energy 2014, 4, 123-131. [CrossRef] 
24. Wang, X.F.; Yu, R.M.; Jiang, C.Y.; Hu, W.G.; Ding, Y.; Peng, W.B.; Li, S.; Wang, Z.L. Piezotronic Effect Modulated Heterojunction Electron Gas in AlGaN/AlN/GaN Heterostructure Microwire. Adv. Mater. 2016, 33, 7234-7242. [CrossRef]

25. Zhu, G.; Lin, Z.H.; Jing, Q.S.; Bai, P.; Pan, C.F.; Yang, Y.; Zhou, Y.S.; Wang, Z.L. Toward Large-Scale Energy Harvesting by a Nanoparticle-Enhanced Triboelectric Nanogenerator. Nano Lett. 2013, 2, 847-853. [CrossRef] [PubMed]

26. Wu, C.S.; Wang, X.; Lin, L.; Guo, H.Y.; Wang, Z.L. Based Triboelectric Nanogenerators Made of Stretchable Interlocking Kirigami Patterns. ACS Nano 2016, 4, 4652-4659. [CrossRef] [PubMed]

27. Tang, W.; Han, Y.; Han, C.B.; Gao, C.Z.; Cao, X.; Wang, Z.L. Self-Powered Water Splitting Using Flowing Kinetic Energy. Adv. Mater. 2015, 2, 272-276. [CrossRef] [PubMed]

28. Li, Z.L.; Chen, J.; Guo, H.Y.; Fan, X.; Wen, Z.; Yeh, M.H.; Yu, C.W.; Cao, X.; Wang, Z.L. Triboelectrification-Enabled Self-Powered Detection and Removal of Heavy Metal Ions in Wastewater. Adv. Mater. 2016, 28, 2983-2991. [CrossRef]

29. Li, Z.L.; Chen, J.; Zhou, J.J.; Zheng, L.; Pradel, K.C.; Fan, X.; Guo, H.Y.; Wen, Z.; Yeh, M.H.; Yu, C.W.; et al. High-efficiency ramie fiber degumming and self-powered degumming wastewater treatment using triboelectric nanogenerator. Nano Energy 2016, 22, 548-557. [CrossRef]

30. Li, Z.L.; Shen, J.L.; Abdalla, L.; Yu, J.Y.; Ding, B. Nanofibrous membrane constructed wearable triboelectric nanogenerator for high performance biomechanical energy harvesting. Nano Energy 2017, 36, 341-348. [CrossRef]

31. Harada, M.; Araki, S.; Kimura, T.; Shibahara, T.; Lwasaki, T.; Okoshi, T.; Terada, S.; Terada, M. New separator with hydrophilic surface treatment for flooded-type lead-acid battery. J. Energy Storage 2018, 16, 197-202. [CrossRef]

32. Deyab, M.A. Ionic liquid as an electrolyte additive for high performance lead-acid batteries. J. Power Source 2018, 390, 176-180. [CrossRef]

33. Ye, B.U.; Kim, B.J.; Ryu, J.; Lee, J.Y.; Bail, J.M.; Hong, K. Electrospun ion gel nanofibers for flexible triboelectric nanogenerator: Electrochemical effect on output power. Nanoscale 2015, 39, 16189-16194. [CrossRef]

34. Yu, B.; Yu, H.; Huang, T.; Wang, H.Z.; Zhang, B.M.; Zhu, M.F. Sinusoidal alternating output of a triboelectric nanogenerator array with asymmetric-layer-based units. Nanoscale 2018, 10, 13730-13736. [CrossRef]

35. Niu, S.M.; Wang, S.; Lin, L.; Liu, Y.; Zhou, Y.S.; Hu, Y.H.; Wang, Z.L. Theoretical Study of Contact-Mode Triboelectric Nanogenerators as an Effective Power Source. Energy Environ. Sci. 2013, 12, 3576-3583. [CrossRef]

36. Zhang, H.L.; Yang, Y.; Su, Y.J.; Chen, J.; Hu, C.G.; Liu, Y.; Wong, C.P.; Bando, Y.S.; Wang, Z.L. Triboelectric nanogenerator as self-powered active sensors for detecting liquid/gaseous water/ethanol. Nano Energy 2013, 2, 693-701. [CrossRef]

37. Guo, H.Y.; Pu, X.J.; Chen, J.; Meng, Y.; Yeh, M.H.; Liu, G.L.; Tang, Q.; Chen, B.; Liu, D. A highly sensitive, self-powered triboelectric auditory sensor for social robotics and hearing aids. Sci. Rob. 2018, 3, 2516. [CrossRef]

38. Chen, X.X.; Han, M.D.; Chen, H.T.; Cheng, X.L.; Song, Y.; Su, Z.M.; Jiang, Y.G.; Zhang, H.X. A wave-shaped hybrid piezoelectric and triboelectric nanogenerator based on P (VDF-TrFE) nanofibers. Nanoscale 2017, 9, 1263-1270. [CrossRef]

39. Zhang, X.S.; Han, M.D.; Wang, R.X.; Zhu, F.Y.; Li, Z.H.; Wang, W.; Zhang, H.X. Frequency-multiplication high-output triboelectric nanogenerator for sustainably powering biomedical microsystems. Nano Lett. 2013, 13, 1168-1172. [CrossRef] [PubMed]

40. Shen, J.L.; Li, Z.L.; Yu, J.Y.; Ding, B. Humidity-resisting triboelectric nanogenerator for high performance biomechanical energy harvesting. Nano Energy 2017, 40, 282-288. [CrossRef]

41. Liu, T.; Yin, Y.S.; Chen, S.G.; Chang, X.T.; Cheng, S. Super-hydrophobic surfaces improve corrosion resistance of copper in seawater. Electrochim. Acta 2007, 52, 3709-3713. [CrossRef]

42. Syrett, B.C. Erosion-corrosion of copper-nickel alloys in sea water and other aqueous environments-A literature review. Corrosion 1976, 6, 242-252. [CrossRef]

(C) 2019 by the authors. Licensee MDPI, Basel, Switzerland. This article is an open access article distributed under the terms and conditions of the Creative Commons Attribution (CC BY) license (http://creativecommons.org/licenses/by/4.0/). 